\title{
EVALUATION OF MANNHEIM PERITONITIS INDEX (MPI) SCORING SYSTEM IN PROGNOSIS OF PATIENTS WITH PERITONITIS DUE TO HOLLOW VISCOUS PERFORATION
}

\author{
Mahammad Ali Sutar1, Ramakrishna Yaradhimmaiah², Nikhath Ingva Arshi3 \\ ${ }^{1}$ Senior Resident, Department of General Surgery, Srinivas Institute of Medical Sciences and Research Centre, Mukka, Mangalore. \\ ${ }^{2}$ Associate Professor, Department of General Surgery, Srinivas Institute of Medical Sciences and Research Centre, Mukka, Mangalore. \\ 3Junior Resident, Department of Obstetrics and Gynaecology, Srinivas Institute of Medical Sciences and Research Centre, Mukka, \\ Mangalore.
}

\section{ABSTRACT}

\section{BACKGROUND}

Evaluation of Mannheim Peritonitis Index (MPI) scoring system in prognosis of patients with peritonitis due to hollow viscous perforation.

\section{METHODS}

Since it is a prospective study, all the eligible cases that are encountered during the period of study will be taken up in the study. Number of patients included in the study was 60 , out of which 47 were males and 13 were females.

\section{RESULTS}

Statistical analysis was done by using descriptive and inferential using chi-square test, sensitivity, specificity, ROC curve. The software used in the analysis were SPSS 17.0 and Graph Pad Prism 5.0 and $\mathrm{p}<0.05$ is considered as level of significance ( $<<0.05$ ).

\section{CONCLUSIONS}

Age $>50$ years seems to have an adverse effect on the outcome in perforative peritonitis. The impact of sex on outcome could not be conclusively proved, even though females seem to have poorer prognosis. The type and extent of peritoneal contamination seems to have a bearing on mortality. Patients with diffuse peritonitis and with faecal contamination do worse. Delayed presentation has an important adverse effect on both mortality and morbidity. However, this is beyond the control of the surgeon.

\section{KEYWORDS}

Hollow Viscous Perforation, Mannheim Peritonitis Index (MPI), Peritonitis.

HOW TO CITE THIS ARTICLE: Sutar MA, Yaradhimmaiah R, Arshi NI. Evaluation of Mannheim peritonitis index (MPI) scoring system in prognosis of patients with peritonitis due to hollow viscous perforation. J. Evolution Med. Dent. Sci. 2016;5(31):

1626-1630, DOI: $10.14260 /$ jemds/2016/383

\section{INTRODUCTION}

The outcome of surgical intervention whether death or uncomplicated survival, complications or long-term morbidity is not solely dependent on the abilities of the surgeon in isolation. The patient's physiological status, the disease that requires surgical correction, the nature of the operation and the pre-operative and post-operative support services have a major effect on the ultimate outcome. Peritoneum inflammation called peritonitis, presents most commonly due to localized or generalized infection caused from various probable factors. Secondary peritonitis is the most common and follows an intraperitoneal source usually from perforation of hollow viscera. Acute generalized peritonitis coming forth due to underlying hollow viscous perforation is a critical and life-threatening medical condition. It is a common surgical emergency in most of the general surgical units across the world. It is often associated with significant morbidity and mortality. ${ }^{1}$

Financial or Other, Competing Interest: None.

Submission 26-02-2016, Peer Review 22-03-2016,

Acceptance 28-03-2016, Published 16-04-2016.

Corresponding Author:

Mahammad Ali Sutar,

Resident Staff Quarters No. 204,

Srinivas Institute of Medical Sciences,

Mukka, Mangalore-574146,

Karnataka.

E-mail:ali_valiant45@yahoo.co.in

valiant.ali45@gmail.com

DOI: $10.14260 /$ jemds $/ 2016 / 383$
The multifaceted nature of abdominal surgical infections makes it difficult to precisely define the disease and to assess its severity and therapeutic progress. Both the anatomic source of infection and to a greater degree the physiologic compromise it inflicts affects the outcome. The systematic approach to quantifying illness in critically ill patients like peritonitis is a recent phenomenon. Early and objective classification of the severity of peritonitis may help in selecting patients for aggressive surgical approach. Highrisk patients require timely and aggressive treatment, especially in severe peritonitis and to select them reasonably well; evaluation through prognostic scoring is an approach of choice.

Early prognostic evaluation is desirable to be able to select high-risk patients for more aggressive treatment, especially in severe peritonitis. ${ }^{1}$ The prognosis and outcome of peritonitis depends upon the interaction of many factors including patient-related factors, disease-specific factors and diagnostic and therapeutic interventions. Categorizing patients into different risk groups would help prognosticate the outcome, select patients for intensive care and determine operative risk, thereby helping to choose the nature of the operative procedure, e.g. damage control vs. definitive procedure. ${ }^{2}$ Various scoring systems have been used to assess the prognosis and outcome of peritonitis. Those used include the Mannheim Peritonitis Index (MPI) (1983), the Acute Physiological and Chronic Health Evaluation Score (APACHE II) (1985), the Peritonitis Index Altona (PIA).

The Sepsis Severity Score (1983) and the Physiological and Operative Severity Score for Enumeration of Mortality 
and Morbidity (POSSUM). ${ }^{3}$ The MPI is one of the simplest scoring systems in use that allows the surgeon to easily determine risk during initial surgery. It is a disease specific score based on easy to handle clinical parameters. The recollection of retrospective data is possible and valid, because MPI only requires information routinely found in surgical registers. Early evaluation of severity of lesion using Mannheim Peritonitis Index (MPI) allows us to estimate the possibility of patient survival. Various authors have reported that MPI provides a more reliable means of risk evaluation and prognosis. ${ }^{2}$

\section{AIMS AND OBJECTIVES}

Evaluation of Mannheim Peritonitis Index (MPI) scoring system in prognosis of patients with peritonitis due to hollow viscous perforation.

\section{MATERIALS AND METHODOLOGY}

This study will be conducted at Kerudi Hospital and Research Centre, Bagalkot, Karnataka, during period of October 2012 to October 2013

\section{Study Design}

Prospective interventional study.

\section{Source of Data}

As this study is prospective; all patients with diagnosis of peritonitis due to hollow viscous perforation after going through inclusion-exclusion criteria will be evaluated for the study.

\section{Sample Size}

Since it is a prospective study, all the eligible cases that are encountered during the period of study were taken up in the study.

\section{Inclusion Criteria}

Patients with clinical suspicion and investigatory support for the diagnosis of peritonitis due to hollow viscous perforation who are later confirmed by intraop findings.

\section{Various Aetiologies causing such Features Include}

- Acid peptic disease.

- Typhoid.

- Tuberculosis.

- Gangrenous cholecystitis.

- Appendicitis.

- Malignancy.

\section{Exclusion Criteria}

1. Patients with hollow viscous perforation due to trauma.

2. Patients with associated injuries to other organs.

3. Patients with associated vascular, neurogenic injuries.

\section{Mannheim Peritonitis Index (1983). ${ }^{4}$}

The MPI analyses 8 prognostically significant factors. Points were given to each factor as given in Table 9. Points were added for each factor present and the MPI score was calculated by adding these points as given in Table 1 .

\begin{tabular}{|c|c|}
\hline Risk Factor & Points \\
\hline Age $>50$ yrs. & 5 \\
\hline Female sex & 5 \\
\hline Organ failure & 7 \\
\hline Malignancy & 4 \\
\hline $\begin{array}{c}\text { Preoperative duration } \\
\text { of peritonitis }>24 \mathrm{~h}\end{array}$ & 4 \\
\hline Origin of sepsis not colonic & 4 \\
\hline $\begin{array}{c}\text { Diffuse generalized } \\
\text { peritonitis }\end{array}$ & 6 \\
\hline \multicolumn{2}{|l|}{ Exudates } \\
\hline Clear & 0 \\
\hline Cloudy, purulent & 6 \\
\hline Faecal & 12 \\
\hline \multicolumn{2}{|l|}{ Definitions of organ failure } \\
\hline Kidney & $\begin{array}{c}\text { Creatinine level }>177 \mathrm{umol} / \mathrm{L} \\
\text { Urea }>167 \mathrm{mmol} / \mathrm{L} \\
\text { Oliguria }<20 \mathrm{~mL} / \mathrm{h}\end{array}$ \\
\hline Lung & $\begin{array}{l}\mathrm{PO}_{2}<50 \mathrm{mmHg} \\
\mathrm{PCO}_{2}>50 \mathrm{mmHg}\end{array}$ \\
\hline Shock & $\begin{array}{l}\text { Hypodynamic or } \\
\text { hyperdynamic }\end{array}$ \\
\hline Intestinal obstruction & $\begin{array}{l}\text { Paralysis }>24 \mathrm{~h} \text {. or complete } \\
\text { mechanical obstruction }\end{array}$ \\
\hline
\end{tabular}

Patients were divided into survivors and non-survivors, and scores were compared between groups. All the patients were followed up till the hospital stay. Mortality was defined as death occurring during hospital stay. The value of each scoring system was tested in prognosticating the outcome of patients.

\section{OBSERVATIONS AND RESULTS}

Statistical analysis was done by using descriptive and inferential using chi-square test, sensitivity, specificity, ROC curve. The software used in the analysis were SPSS 17.0 and Graph Pad Prism 5.0 and $\mathrm{p}<0.05$ is considered as level of significance $(\mathrm{p}<0.05)$. MPI score was tested by quantitative methods based on statistical criteria. The following statistical tests were done to know the ability to predict outcome.

The total number of included patients in the current study is 60 .

Different Statistical Analyses for these Patients is as follows

\section{Sex Distribution}

\begin{tabular}{|c|c|}
\hline Gender & Percentage (No.) \\
\hline Male & $78.30 \%(47)$ \\
\hline Female & $21.70 \%(13)$ \\
\hline Total & $\mathbf{1 0 0 \% ( 6 0 )}$ \\
\hline \multicolumn{2}{|c|}{ Table 2 } \\
\hline
\end{tabular}

Out of the 60 included patients, female were 13 (21.7\%) while males were 47 (78.3\%).

Age Distribution

\begin{tabular}{|c|c|c|}
\hline \multirow{4}{*}{ Age (yrs.) } & $10-19$ & $5(8.33 \%)$ \\
\cline { 2 - 3 } & $20-29$ & $12(20 \%)$ \\
\cline { 2 - 3 } & $30-39$ & $11(18.33 \%)$ \\
\cline { 2 - 3 } & $40-49$ & $10(16.67 \%)$ \\
\cline { 2 - 3 } & $\geq 50$ & $22(36.67 \%)$ \\
\hline \multicolumn{3}{|c|}{ Table 3 } \\
\hline
\end{tabular}


The age group 10-19 yrs. have 5 patients, which account for $8.33 \%$ of the total included patients. The age groups 20 $29,30-39,40-49$ have $12,11,10$ patients respectively. The age group more than 50 has 22 patients.

\section{Clinical Features}

The clinical features of the included 60 patients and the details of their distribution is as follows.

\begin{tabular}{|c|c|c|}
\hline \multirow{2}{*}{ Fever } & Yes & $19(31.7 \%)$ \\
\cline { 2 - 3 } & No & $41(68.3 \%)$ \\
\hline \multirow{2}{*}{ Vomiting } & Yes & $4(6.7 \%)$ \\
\cline { 2 - 3 } & No & $56(93.3 \%)$ \\
\hline \multirow{2}{*}{ Anorexia } & Yes & $16(26.7 \%)$ \\
\cline { 2 - 3 } & No & $44(73.3 \%)$ \\
\hline \multirow{2}{*}{ Constipation } & Yes & $25(41.7 \%)$ \\
\cline { 2 - 3 } & No & $35(58.3 \%)$ \\
\hline \multirow{2}{*}{ Abdominal Distension } & No & $3(5 \%)$ \\
\cline { 2 - 3 } & Yes & $57(95 \%)$ \\
\hline \multirow{2}{*}{ Duration of Peritonitis } & $>24 \mathrm{hr}$. & $22(36.7 \%)$ \\
\cline { 2 - 3 } & $<24 \mathrm{hr}$. & $38(63.3 \%)$ \\
\hline \multicolumn{2}{|c}{ Table 4 } \\
\hline \multirow{2}{|c}{}
\end{tabular}

The Intraoperative Findings for site of Perforation of all Included 60 Patients is as follows

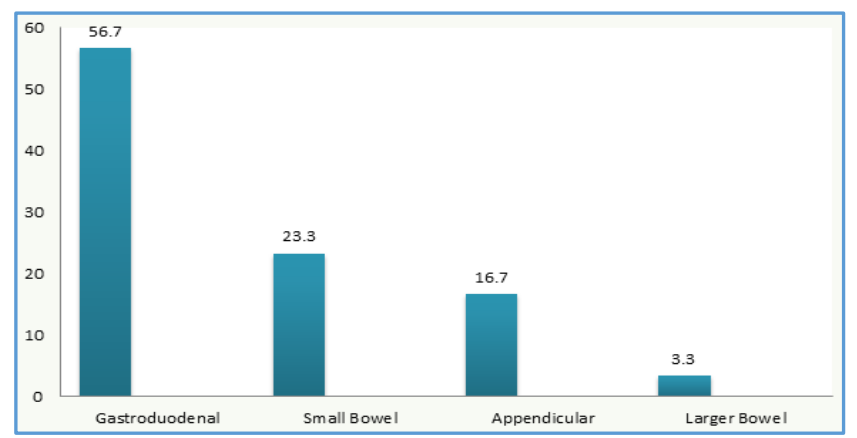

The Mannheim peritonitis index is calculated for each patient. The patients are grouped depending upon the score into three categories, i.e. category 1 -score $<15$, category $2-$ score 15-26 and category 3-score more $>26$.

The mean of the score is 18.63 , while 1 standard deviation is 7.18 , the range of the scores of the included patients is from 6 to 33 .

\begin{tabular}{|c|c|c|}
\hline Site of Perforation & No. of Patients & Percentage (\%) \\
\hline Gastroduodenal & 34 & 56.7 \\
\hline Small Bowel & 14 & 23.3 \\
\hline Appendicular & 10 & 16.7 \\
\hline Larger Bowel & 2 & 3.3 \\
\hline \multicolumn{3}{|c|}{ Table 5 } \\
\hline
\end{tabular}

\begin{tabular}{|c|c|c|}
\hline MPI Score & No. of Patients & Percentage (\%) \\
\hline$<15$ & 24 & 40.0 \\
\hline $15-26$ & 29 & 48.3 \\
\hline$>26$ & 7 & 11.7 \\
\hline Total & $\mathbf{6 0}$ & $\mathbf{1 0 0 . 0}$ \\
\hline Table 6: The Category Wise Distribution of the Patients \\
\hline
\end{tabular}

Two deaths recorded out of the 60 patients. One of them had multiple ileal tubercular perforation and the other had ileo-ileal anastomotic leak.

\section{Stay in the Hospital}

The hospital stay of patients in weeks is found to be in direct relation of their score. Patients with less score, i.e. in category 1 of MPI score less than 15 tend to stay for approximately a week in the hospital. Patients with score more than 26 stayed in the hospital for approximately 3 weeks. Thus making the stay in the hospital significant in relation to the MPI score $(\mathrm{p}=0.000)$.

Fig. 1

\begin{tabular}{|c|c|c|c|c|c|c|c|}
\hline \multirow{2}{*}{$\begin{array}{l}\text { Stay in } \\
\text { Weeks }\end{array}$} & \multicolumn{2}{|c|}{$<15$} & \multicolumn{2}{|c|}{$15-26$} & \multicolumn{2}{|c|}{$>26$} & \multirow{2}{*}{$\begin{array}{c}\mathbf{P} \\
\text { Value }\end{array}$} \\
\hline & No & Dead & No & Dead & No & Dead & \\
\hline $1 \mathrm{wk}$. & $\begin{array}{c}21 \\
(35 \%)\end{array}$ & - & $\begin{array}{c}21 \\
(35 \%)\end{array}$ & - & - & - & \multirow{3}{*}{$\begin{array}{c}45.38 \\
\mathrm{P}=0.000\end{array}$} \\
\hline $2 \mathrm{wk}$. & $\begin{array}{c}3 \\
(5 \%) \\
\end{array}$ & - & $\begin{array}{c}8 \\
(13.33 \%) \\
\end{array}$ & - & $\begin{array}{c}2 \\
(3.33 \%) \\
\end{array}$ & - & \\
\hline $3 \mathrm{wk}$. & - & - & - & - & $\begin{array}{c}5 \\
(8.55 \%)\end{array}$ & $\begin{array}{c}2 \\
(3.33 \%)\end{array}$ & \\
\hline
\end{tabular}

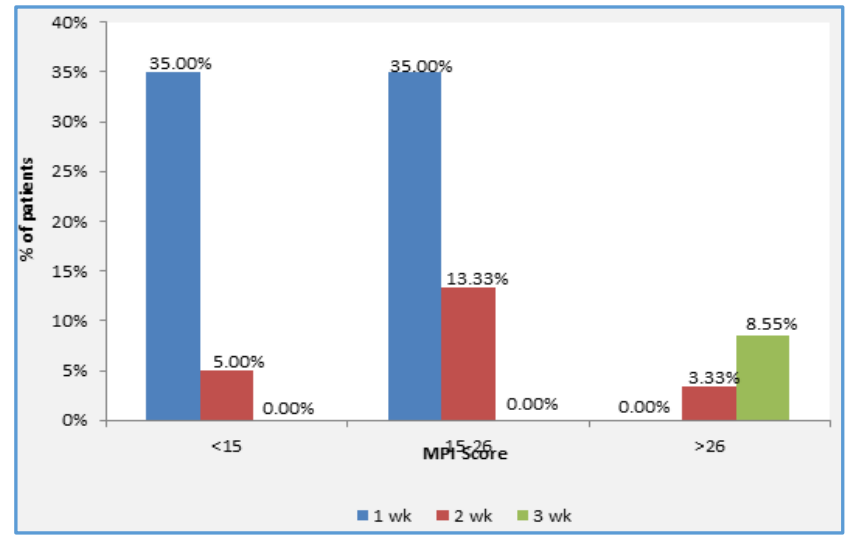

Fig. 2

\section{DISCUSSION}

Clinical profile of the patients included in the current study is comparable with the previous studies, except for maximum of our patients presented with vomiting and distension of abdomen; $100 \%$ patients had pain abdomen, as it was the most important presenting complaint of the patients. The most significant predictive factors for morbidity/mortality in this study were the age, presence of organ failure, duration of symptoms more than $24 \mathrm{~h}$., the origin of sepsis and the presence of faecal peritoneal fluid. However, gender and presence of diffuse generalised peritonitis were not significant predictors. Wabwire et al. ${ }^{6}$ found as predictive factors the female gender, age above 50 years, presence and number of organ dysfunction, character of exudate extent. Sailer et al. ${ }^{7}$ whose studies focused on generalized peritonitis 
reported similar findings only that he found preoperative duration to significantly influence eventual mean MPI from 23.2 to 29 points. Bielecki et al. ${ }^{8}$ found a mean of 24.2 points among patients with large bowel perforation. In our study, 60 patients were recruited, 13 and 47 being females and males respectively. This pattern is not similar to studies from the developed countries, which show an even gender distribution or a slight preponderance of either sex.7,9,10 However, Wabwire et al. ${ }^{6}$ found a male predominance with a sex ratio of $4: 1$, which is comparable with the current study. The majority of our patients were young with a mean age of 40.75 years and $36.67 \%$ of the study group falling in the $>50$ years age category. Melero. ${ }^{11}$ in Mexico reported almost similar distribution with a mean of 34.6 years, but studies from Europe show a much older age group with a range of 44-64.8 years, which is similar to the statistics of the current study. The ROC curve for mortality showed a predictive power of 0.991 . In this study, MPI had a sensitivity of $91.23 \%$ and specificity of $62.56 \%$ at an MPI of 26 points for morbidity. At the cut-off of 29 , MPI had a sensitivity of $68.25 \%$ and specificity of $99.19 \%$.

These values are comparable to the studies by $\mathrm{F}$. Ntirenganya et al. ${ }^{12}$ Biondo et al. ${ }^{13}$ Billing et al. ${ }^{9}$ Biondo et al. ${ }^{13}$ reported a predictive power of 0.725 at an MPI score of 26 points, while Billing et al..$^{9}$ in a meta-analysis of 2003 patients reported a mean sensitivity of $86 \%$ (54\%-98\%) and specificity of $74 \%(58 \%-97 \%)$ at a score of 26 points. In a study at KNH, Ndonga. ${ }^{14}$ found that perforated duodenal ulcer was the commonest cause of generalized peritonitis at $28 \%$ followed by jejunoileal perforations (19.5\%) and perforated appendicitis (14.6\%). This is comparable to our study with maximum patients having gastroduodenal perforation as the cause of the generalised peritonitis; $58.3 \%$ of the patients included in the current study had gastroduodenal perforation.

The second common cause of the generalised peritonitis is found to be small bowel (jejunum and ileum). Studies from Europe show a different picture with colonic perforation due to diverticular disease and cancer (16-70\%), the leading causes followed by gastroduodenal peptic ulcer perforation $(16 \%)$ and perforated appendicitis (8\%).5,7,9,15,16 The mortality of the patients in the category of score less than 15 is $0 \%$, also the mortality in the score category $16-26$ is $0 \%$. In total 2 deaths occurred in the present study, both in the last category of score more than 26 (28.57\% mortality).

This finding is correlating with most of the studies, stating that the mortality increases exponentially with the score. In a study by Qureshi AM et al. ${ }^{17}$ the mortality of the patients is $28.1 \%$ in the score category of more than 26 . Same finding of exponential rise of mortality has been reported in the study by Chandrashekhar $\mathrm{N}$ et al.18 A Korean study by Koen Hwan Park et al. ${ }^{19}$ considers MPI score of more than 25, along with preoperative shock and colonic perforation to be one of the important predictive factor for postoperative intensive management associated with mortality.

\section{CONCLUSION}

Age $>50$ years seems to have an adverse effect on the outcome in perforative peritonitis. The impact of sex on outcome could not be conclusively proved, even though females seem to have poorer prognosis. The type and extent of peritoneal contamination seem to have a bearing on mortality. Patients with diffuse peritonitis and with faecal contamination do worse. Delayed presentation has an important adverse effect on both mortality and morbidity. However, this is beyond the control of the surgeon. Only adequate health education and a proper referral mechanism can help in this regard. This scoring system helps to determine the risk of patient preoperatively as well as assist the surgeon in his decision regarding surgery.

Definitive surgery can be done safely in low score patients; aggressive, newer modalities of treatment need to be tried in high score patients. Cases of peritonitis carry a high mortality which can be reduced by early diagnosis, risk stratification and appropriate treatment based on risk score. In our study, it was found that when MPI score increased mortality increased, so MPI score proved to be a useful tool to predict the mortality in patients of peritonitis. We propose that MPI would definitely be an effective objective aid in the hands of surgeons dealing with such patients in intensive care units.

\section{REFERENCES}

1. Ashish Ahuja, Ravinder Pal. Prognostic scoring indicator in evaluation of clinical outcome in intestinal perforations. Journal of Clinical and Diagnostic Research 2013;7(9):1953-5.

2. Ajaz Ahmad Malik, Khurshid Alam Wani, Latif Ahmad Dar, et al. Mannheim peritonitis index and APACHE II prediction of outcome in patients with peritonitis. Ulus Travma Acil Cerrahi Derg 2010;16(1):27-32.

3. Ukwenya AY, Ilyasu Muhammad, Nmadu PT. Assessing the severity of intraabdominal infections; the value of APACHE II scoring system. Nigerian jounal of surgical Research 2006;8(1-2):24-9.

4. Wacha H, Linder MM, Feldman U, et al. Mannheim peritonitis index-prediction of risk of death from peritonitis: construction of a statistical and validation of an empirically based index. Theoretical Surg 1987;1:169-77.

5. Demmel N, Muth G, Maag K, et al. Prognostic scores in peritonitis: the mannheim peritonitis index or APACHE II? Langenbecks Archivfür Chirurgie 1994;379(6):34752.

6. Wabwire B. Stratified outcome evaluation in peritonitis. M Med (Surgery) UoN dissertation 2009.

7. Seiler CA, Brugger L, Forssmann U, et al. Conservative surgical treatment of diffuse peritonitis. Surgery 2000;127(2):178-84.

8. Bielecki K, Karminski P, Klukowski M. Large bowel perforation: morbidity and mortality. Tech Coloproctol 2002;6(3):177-82.

9. Billing A, Frölich D, Schildberg FW. Prediction of outcome using the mannheim peritonitis index in 2003 patients peritonitis study group. $\mathrm{Br} \quad \mathrm{J}$ Surg 1994;81(2):209-13.

10. Correia MM, Thuler LCS, Velasco E, et al. Prediction of death using the mannheim peritonitis index in oncologic patients. Revista Brasileira de Cancerologia 2001;47(1):63-8.

11. Melero A. Mannheim peritonitis index validation study at the hospital general de durango. Cirugiay Cirujianos 2002;70(4):217-25. 
12. Ntirenganya F, Ntakiyiruta G, Kakande I. Prediction of outcome using the mannheim peritonitis index in patients with peritonitis at kigali university teaching hospital. East Cent Afr J surg 2012;17(2):52-64.

13. Biondo S, Ramos E, Fraccalvieri D, et al. Comparative study of left colonic peritonitis severity score and mannheim peritonitis index. Br J Surg 2006;93 (5):61622.

14. Ndonga AK. A study of atraumaticjejunoileal perforations at kenyatta national hospital. M Med (Surgery) UoN dissertation 2002;28-60.

15. Marshall JC. Intra-abdominal infections. Microbes \& Infection 2004;6(11):1015-25.

16. Martin RF, Rossi RL. The acute abdomen an overview and algorithms. Surgical Clinics of North America 1997;77(6):1227-43.
17. Quereshi AM, Zafar A, Khurram S, et al. Predictive power of mannheim peritonitis index. Journal of the College of Physicians and Surgeons Pakistan 2005;15(11):693-6.

18. Chandrashekar N, Prabhakar G, Gurukiran C, et al. Study of prognostic factors in perforative peritonitis. Journal Of Evolution of Medical and Dental Sciences 2013;2(30):5568-74.

19. Keon Hwan Park, Pyong Wha Choi, Jae Il Kim, et al. Prognostic factors for complication and mortality of colonic perforation. J Korean Soc Coloproctol 2009;25(3):143-9. 